\title{
The Influence of High-Involvement Human Resources Practices on Proactive Behavior
}

\author{
Mingshu Chen ${ }^{1}$,Junrong Wang ${ }^{1, *}$ \\ ${ }^{1}$ School of Business, Central South University, Changsha 410000, China
}

\begin{abstract}
This research is based on the theory of self-determination, and focuses on how high-involvement human resources practices can promote employee' proactive behavior. Through the analysis of 328 questionnaire data, the results show that high-involvement human resources practices promote proactive behavior, and this process is realized through the intermediary effect of thriving at work. This research broadens the theoretical research on the impact of high-involvement human resources practices, and explores the mechanism and practical significance of the organization's adoption of effective human resource practices to promote proactive behavior.
\end{abstract}

\section{Introduction}

With the increasing uncertainty of the external environment, the sustainable development of organizations is facing huge challenges. Due to the limited ability and energy of organization managers, companies will increasingly rely on employees to challenge the status quo, promote proactive behavior ${ }^{[1,2]}$. Relying on the proactive behavior of employees can not only improve the productivity and efficiency of the organization, but also the fundamental guarantee for the survival and development of the organization.

Proactive behavior refers to employees voluntarily making constructive efforts to initiate organizational functional changes in order to carry out work more effectively in their own positions, departments or organizational contexts ${ }^{[3]}$. It focuses not only on identifying issues and opportunities for change, but also taking actions to implement change plans, or make actual changes to working methods and procedures ${ }^{[4]}$. However, many employees still tend to passively accept work tasks and arrangements, passively adapt to the environment ${ }^{[5]}$. Therefore, how to effectively promote proactive behavior has become an important problem. Existing studies have mainly explored the important factors affecting proactive behavior from the individual level and the organizational level, such as personal self-efficacy, proactive personality ${ }^{[6]}$, emotional, leadership $\operatorname{style}^{[7,}{ }^{8]}$ and organizational environment ${ }^{[9]}$. However, they have neglected the human resource management that is most likely to affect employee behavior. High participation in human resource practice improves employees' psychological security and intrinsic motivation ${ }^{[10,11]}$, and is likely to promote employees' proactive behavior.

\section{Materials}

\section{1 high-involvement human resources practices and proactive behavior}

High-involvement human resources practices take employee participation as the core. It not only promotes employees to work hard, but also stimulates their work vitality and creativity, and enhances their work abilities and skills ${ }^{[12]}$. The theoretical framework of highinvolvement human resources practices includes five dimensions: competence development, empowerment, fair organizational rewards, recognition and information sharing ${ }^{[13,14]}$. Analyze the relationship between highinvolvement human resources practices and change responsible behaviors from five dimensions:

Empowerment gives employees work autonomy and decision-making power, so that employees have the opportunity to optimize the work process at work and enhance their own sense of efficacy and control of work; competence development (such as training) improves employees' problem-solving ability and initiative ${ }^{[15]}$;information sharing makes employees feel the trust from the organization, and help employees understand the key factors and potential problems in the work $^{[16]}$; recognition enhance employees' psychological safety and organizational identification, and reduce the perceived risk of acting as a change ${ }^{[17]}$; fair organizational rewards improve employees' sense of fairness in return, and enable employees to internalize their work goals as a means to improve their self-worth, thereby enhancing employees' intrinsic motivation to proactive behavior ${ }^{[18]}$.

Pay attention to employee participation through highinvolvement human resources practices, improve

*Corresponding author: $2815926719 @ q q . c o m$ 
employee organizational recognition, and promote employee proactive behavior:

H1: High-involvement human resources practices are positively related to proactive behavior.

\section{2 high-involvement human resources practices and proactive behavior via thriving at work}

Thriving at work refers to the state where individuals experience both learning and vitality at the same time ${ }^{[19]}$. Learning and vitality reflect the two dimensions of cognition and emotion of individual growth. Vitality represents the individual's energy and enthusiasm for work; learning refers to the individual's feelings of building self-confidence and enhancing abilities by acquiring knowledge and skills. Thriving at work help individuals adapt to the working environment and promote their growth and development.

Based on the theory of self-determination, Spreitzer et al. (2005) proposed " a socially embedded model of thriving at work" ${ }^{19]}$. The model points out that contextual features such as decision-making discretion, broad information sharing, and climate of trust and respect will promote individual agentic work behaviors by satisfying the three basic psychological needs of autonomy, competence, relatedness. The satisfaction of the three basic needs provides the necessary psychological nutrients for the motivational behavior, growth and development of employees ${ }^{[20,21]}$. This study believes that high-involvement human resources practices as a situational factor in an atmosphere of autonomous decision-making, information sharing, and trust and respect will improve the level of thriving at work by meeting the basic psychological needs of employees.

First of all, under the influence of high-involvement human resources practices, the organization is fully empowered, and employees have the right to independently decide on their work methods, work plans,

and decision-making, which is conducive to stimulating employee autonomy. In addition, competence development activities such as training enhance employees' work abilities, and organizing information sharing is conducive to enhancing employees' ability to detect early and take countermeasures. The organization's adoption of reasonable suggestions from employees enhances employees' competence. Furthermore, the atmosphere of trust and respect, as well as the recognition and spiritual encouragement from the organization, meets the relatedness of employees and contributes to the improvement of employees' well-being.

According to SDT theory, the satisfaction of autonomy needs, competence needs and relatedness needs is conducive to the internalization of external motivations [22]. Therefore, high participation human resource practices are positively related to thriving at work.

The realization of thriving at work will encourage employees to proactive behavior. Studies have shown that thriving at work is positively related to employee changeoriented behavior. First of all, individuals who reach the state of thriving at work tend to take more proactive behaviors to maintain future thriving at work. Secondly, learning at work promotes continuous improvement of employees, enhances their ability to discover and solve problems, thereby inspiring employees' willingness to change the status quo. Third, the vitality dimension of thriving at work is very related to internal vitality, and is the main driving force that stimulates individual active behavior. As a positive emotion ${ }^{[23,24]}$, "vitality" stimulate employees' willingness to act actively ${ }^{[25]}$, expand the depth of thinking activities, and help individual thinking being active, enhancing the tendency of individuals to behaviors $^{[24]}$, and inspiring employees to proactive behavior. Based on above, hypothesis $\mathrm{H} 2$ is proposed:

$\mathrm{H} 2$ : Thriving at work promote proactive behavior and thriving at work mediates the relationship between highinvolvement human resources practices and employee proactive behavior.

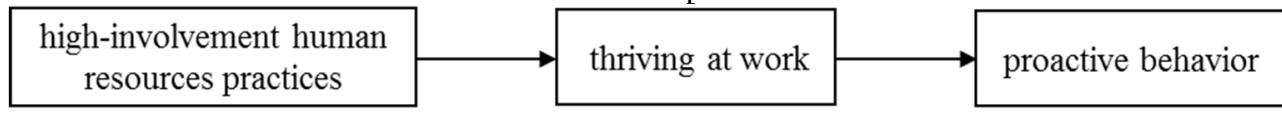

Fig.1 Research model

\section{Method}

\subsection{Participants}

This study collects data through electronic questionnaires and paper questionnaires. In this survey, a total of 380 questionnaires were distributed and 367 questionnaires were recovered. After deleting the unqualified questionnaires, a total of 328 valid data were obtained, and the total effective recovery rate was $89.37 \%$.

Among the valid questionnaires, males accounted for $50.3 \%$ and females accounted for $49.7 \%$; the age group was mainly $26-30$ years old, accounting for $35.1 \%$; the education background of employees was mainly undergraduate, accounting for $48.8 \%$; the positions of employees were mainly grassroots and middle-level. A total of $93.6 \%$; the working years is mainly 3 years or less, accounting for $45.7 \%$.

\subsection{Measures}

The scales used in this study are all derived from mature scales, which have good reliability and validity. The questionnaire uses Likert 5-point scoring, and employees self-evaluate based on their personal perception. 1 represents strongly disagree with the item description, and 5 represents strongly agree with the item description.

1. High-involvement human resources practices. The scale compiled by Yang ${ }^{[12]}$ from the perspective of employee perception. The scale has 13 items in 5 dimensions. The Cronbach's $\alpha$ value of this scale in this study is 0.852 .

2.Thriving at work. A two-dimensional scale including 
vitality and learning compiled by Porath et al. ${ }^{[26]}$ is used. The Cronbach's $\alpha$ value of this scale is 0.87 .

3.Proactive behavior. Using the measurement items of Griffing et al. ${ }^{[3]}, 6$ items were used to measure the behavior of proactive behavior. In this study, Cronbach's $\alpha$ was 0.854

Control variables: select key gender, age, education, and working years for control variables.

\section{Results}

\subsection{Common Method Bias}

In this study, data collected through employee selfevaluation is prone to common method bias. Therefore, we use the two methods to test the common method bias. First, use the Harman single factor detection method to aggregate all the questions on the same common factor, and build a single factor structural equation Ml. The results show that the single factor fits $(\chi 2=1773.090, \mathrm{df}$ $=405, \chi 2 / \mathrm{df}=4.378, \mathrm{TLI}=0.623, \mathrm{CFI}=0.652$, RMSEA $=0.102, \mathrm{SRMR}=0.084)$ is not ideal (see Table 1$)$.

In addition, this article incorporates all topics into the factor analysis, and the first principal component explains the $30.86 \%$ variation of the total variance without rotation, which is less than $40 \%$. The results show that there is no serious common method bias in the data of this study.

Before testing the theoretical hypothesis, this research first uses M-plus8.3 software to test the discriminant validity of high-involvement human resources practices, thriving at work, and proactive behavior. Analyses indicated that the three-factor model had acceptable fit indices $(\chi 2=698.323, \mathrm{df}=397, \chi 2 / \mathrm{df}=1.759$, TLI $=0.911$, $\mathrm{CFI}=0.914$, RMSEA $=0.055$, SRMR $=0.057$ ) and it is better than other models. Therefore, the three variables in this study showed good discriminant validity.

Table 1. Confirmatory factor analyses of models

\begin{tabular}{|c|c|c|c|c|c|}
\hline Models & $\chi^{2} / d f$ & TLI & CFI & RMSEA & SRMR \\
\hline N1: HIHR,WR,PB & 1.759 & 0.911 & 0.914 & 0.055 & 0.057 \\
\hline N2: HIHR+WR, PB & 3.974 & 0.668 & 0.695 & 0.096 & 0.080 \\
\hline N3: HIHR+PB,WR & 3.944 & 0.671 & 0.698 & 0.096 & 0.081 \\
\hline N4: HIHR+WR+PB & 4.378 & 0.623 & 0.652 & 0.102 & 0.084 \\
\hline
\end{tabular}

Notes: HIHR, high-involvement human resources practices; WR, thriving at work; $\mathrm{PB}$, proactive behavior

\subsection{Descriptive Statical Results}

The descriptive statistics, correlations of each variable are shown in Table 2. The results show that high-involvement human resources practices positively predict thriving at work $(\mathrm{r}=0.38, \mathrm{p}<0.01)$ and proactive behavior $(\mathrm{r}=0.42$, $\mathrm{p}<0.01)$; Thriving at work positively predicts proactive behavior $(\mathrm{r}=0.39, \mathrm{p}<0.01)$.
Table 2 Descriptive Statistics

\begin{tabular}{|l|c|c|c|}
\hline & $\mathrm{M} \pm \mathrm{SD}$ & 1 & 2 \\
\hline $\begin{array}{l}\text { 1.high-involvement } \\
\text { human resources } \\
\text { practices }\end{array}$ & $3.56 \pm 0.56$ & & \\
\hline 2. thriving at work & $3.89 \pm 0.52$ & $0.38^{* *}$ & \\
\hline $\begin{array}{l}\text { 3. proactive } \\
\text { behavior }\end{array}$ & $3.75 \pm 0.52$ & $0.42^{* *}$ & $0.39^{* *}$ \\
\hline
\end{tabular}

\subsection{Hypothesis Testing}

Table3. Regression analysis results

\begin{tabular}{|c|c|c|c|c|c|c|}
\hline \multirow{2}{*}{$\begin{array}{c}\text { Independent } \\
\text { variable }\end{array}$} & \multicolumn{2}{|c|}{ Thriving at Work } & \multicolumn{4}{|c|}{ Proactive Behavior } \\
\cline { 2 - 7 } & M1 & M2 & M3 & M4 & M5 & M6 \\
\hline Gender & -0.06 & 0.01 & -0.05 & -0.01 & -0.01 & -0.01 \\
\hline Age & 0.06 & 0.09 & $0.14^{*}$ & $0.16^{* *}$ & $0.12^{*}$ & $0.12^{* *}$ \\
\hline Education & $0.18^{* *}$ & $0.13^{* *}$ & 0.06 & 0.02 & -0.05 & -0.05 \\
\hline Position & 0.06 & 0.06 & 0.03 & -0.01 & -0.03 & -0.03 \\
\hline Working year & -0.05 & -0.01 & -0.06 & 0.03 & -0.03 & -0.04 \\
\hline HIHR & & $0.43^{* *}$ & & $0.45^{* *}$ & $0.15^{* *}$ & \\
\hline WR & & & & & $0.51^{* *}$ & $0.59^{* *}$ \\
\hline $\mathrm{R}^{2}$ & 0.05 & 0.35 & 0.04 & 0.24 & 0.43 & 0.42 \\
\hline$\triangle \mathrm{R}^{2}$ & 0.05 & $0.30^{* *}$ & 0.04 & $0.12^{* *}$ & $0.20^{* *}$ & 0.38 \\
\hline $\mathrm{F}$ & $3.10^{* *}$ & $18.49^{* *}$ & $2.55^{* *}$ & $16.31^{* *}$ & $34.10^{* *}$ & $37.56^{* *}$ \\
\hline
\end{tabular}

Notes: $* \mathrm{p}<.05 ; * * \mathrm{p}<.01$. HIHR, high-involvement human resources practices; WR, thriving at work. Unstandardized coefficients are reported.

In this study, the mediation effect test was carried out according to the process proposed by Baron and Kenny (1986) ${ }^{[27]}$. M1 shows that among the control variables, only education has a significant impact on thriving at work. M2 shows that high-involvement human resources practices significantly positively predict thriving at work $(\mathrm{b}=0.43, \mathrm{p}<0.01)$, and $\mathrm{R}^{2}$ increases from 0.05 to 0.35 . M6 shows that thriving at work has a significant positive effect on proactive behavior $(b=0.59, \mathrm{p}<0.01)$. In support for Hypothesis 2, thriving at work is significantly related to proactive behavior $(\mathrm{b}=0.51, \mathrm{p}<0.01)$. The positive effect of high-involvement human resources practices is significantly smaller but still significant $(\mathrm{b}=$ 0.15 , p $<0.01$ ), which indicates thriving at work plays a part of the mediating role between high-involvement human resources practices and proactive behavior.

In order to verify the mediation effect more accurately, Bootstrap method is used to test the significance of the mediation effect. The results show that the mediating effect of thriving at work is 0.31 , and the $95 \%$ confidence interval does not contain zero. The direct effect between high-involvement human resources practices and proactive behavior is 0.14 , and the $95 \%$ confidence interval does not include 0 . This result shows that part of the mediating effect of thriving at work is significant. Hypothesis 2 is again supported. 


\section{Discussion}

\subsection{Conclusion}

From the perspective of self-determination theory, this paper examines the influence mechanism and boundary conditions of high-involvement human resources practices on employees' proactive behavior. The following conclusions are drawn: (1) High-involvement human resources practices have significant positive effect on employees' proactive behavior. Although studies have shown that high-involvement human resources practices promote innovation and proactive behavior, no research has focused on whether it has an effect on employees' proactive behavior. These results will broaden our explanatory frameworks on the effects of highinvolvement human resources practices on proactive behavior. (2) Thriving at work mediates the relationship between high-involvement human resources practices and employee proactive behavior. High-involvement human resources practices have an impact on employees' attitudes and behaviors through cognitive and emotional aspects. This research integrates cognitive and emotional influences, enriches the ways to thrive at work, provides a new foothold and research perspective for enhancing thriving at work.

\section{2 research value}

The findings offer some useful practical implications. Organizations which create a supportive atmosphere for high-involvement human resources practices in order to the members adopt proactive behavior. The implementation of high-involvement human resources practices can bring a series of benign effects to individual employees and even the entire organization. Companies should combine their own characteristics, choose a reasonable highinvolvement human resources practices model, and create a good leadership support atmosphere, so that employees can actively participate and exert their own effectiveness.

In addition, managers should cultivate employees' thriving at work. Thriving at work can not only improve individual performance, but also increase employee job satisfaction and reduce employee turnover. Therefore, work organizations are consequential for individuals' growth, development, and health through the cultivation of thriving. Such as provide a climate of trust and respect, great progress can be achieved.

\subsection{Limitations}

First of all, the sample data in this study are all horizontal data. In the future, a longitudinal research design can be adopted to collect questionnaire data from different time points and items to better control the common method bias.

A second potential limitation is that this article only explores the impact of organizational factors on employees' proactive behavior. It lacks the embedding of individual and team level variables. In the future, it can explore the multi-level mechanism of individual, team and organizational factors on employees' proactive behavior. Understand the various factors that prompt employees to proactive behavior in the daily work environment.

\section{References}

1. PARKER $\mathrm{S} \mathrm{K}$, WANG Y, LIAO J. When Is Proactivity Wise? A Review of Factors That Influence the Individual Outcomes of Proactive Behavior[J]. Annual Review of Organizational Psychology and Organizational Behavior, 2019,6(1): 221-248.

2. LiU W, TANGIRALA S, LEE $\mathrm{C}$, et al. New directions for exploring the consequences of proactive behaviors: Introduction to the special issue[J]. Journal of Organizational Behavior, 2019,40(1): 1-4.

3. GRIFFIN M A, NEAL A, PARKER S K. A new model of work role performance: positive behavior in uncertain and interdependent contexts[J]. Academy of Management Journal, 2007.

4. FULLER J B, MARLER L E, HESTER K. Bridge building within the province of proactivity[J]. Journal of Organizational Behavior, 2012,33(8): 1053-1070.

5. ANITA STARZYK S S. When do low-initiative employees feel responsible for change and speak up to managers?[J]. Journal of Vocational Behavior, 2019,115: 103342.

6. WU C, PARKER S K, WU L, et al. When and Why People Engage in Different Forms of Proactive Behavior: Interactive Effects of Self-construals and Work Characteristics[J]. Academy of Management Journal, 2018,61(1): 293-323.

7. LI N, CHIABURU D S, KIRKMAN B L. CrossLevel influences of empowering leadership on citizenship behavior[J]. Journal of Management, 2017,43(4): 1076-1102.

8. OUYANG K, LAM W, WANG W. Roles of gender and identification on abusive supervision and proactive behavior[J]. Asia Pacific Journal of Management, 2015,32(3): 671-691.

9. LIN C, KAO Y, CHEN Y, et al. Fostering changeoriented behaviors: A broaden-and-build model[J]. Journal of Business and Psychology, 2016,31(3): 399-414.

10. TIAN $\mathrm{X}$, ZHAI $\mathrm{X}$. Employee involvement in decision-making: the more the better?[J]. International Journal of Manpower, 2019,40(4): 768782.

11. LI Y, WANG M, Van JAARSVELD D D, et al. From Employee-experienced High-involvement Work System to Innovation: An Emergence-based Human Resource Management Framework[J]. Academy of Management Journal, 2018,61(5): 2000-2019.

12. YANG Y. High-involvement human resource practices, affective commitment, and organizational 
citizenship behaviors[J]. The Service Industries Journal, 2012,32(8): 1209-1227.

13. PARÉ G, TREMBLAY M, MONTRÉAL H. The Influence of high-involvement human resources practices, procedural justice, organizational commitment, and citizenship behaviors on Information technology professionals ' turnover intentions[J]. Group \& Organization Management, 2007,32(3): 326-357.

14. LAWLER III E E. The ultimate advantage:Creating the high-involvement organization[M]. Jossey-Bass, 1992.

15. PARKER S K, BINDL U K, STRAUSS K. Making things happen: A model of proactive motivation[J]. Journal of Management, 2010,36(4): 827-856.

16. SMITH M B, WALLACE J C, VANDENBERG R J, et al. Employee involvement climate, task and citizenship performance, and instability as a moderator[J]. The International Journal of Human Resource Management, 2018,29(4): 615-636.

17. BODLA A A, NINGYU T. Transformative HR practices and employee task performance in hightech firms[J]. Journal of Organizational Change Management, 2017,30(5): 710-724.

18. NOOR A N M, KHALID S A, NOR M N M, et al. Relationship Between High-Involvement Human Resource Practices and Innovative Work Behavior[J]. Advanced Science Letters, 2017,23(8): 7505-7507.

19. GRETCHEN SPREITZER K S J D. A Socially Embedded Model of Thriving at Work[J].
Organization Science, 2005.

20. RYAN R M, DECI E L. Self-determination theory and the facilitation of intrinsic motivation, social development, and well-being[J]. Am Psychol, 2000,55(1): 68-78.

21. CORNELIA NIESSEN I M C S. Thriving when exhausted: The role of perceived transformational leadership[J]. Journal of Vocational Behavior, 2017.

22. DECI E L, RYAN R M. Facilitating optimal motivation and psychological well-being across life's domains[J]. Canadian Psychology, 2008,49(1): 14-23.

23. CARMELI A, SPREITZER G M. Trust, Connectivity, and Thriving: Implications for Innovative Behaviors at Work[J]. The Journal of Creative Behavior, 2009,43(3): 169-191.

24. FREDRICKSON B L. The role of positive emotions in positive psychology: The broaden and build theory of positive emotions[J]. American Psychologist, 2001,56(3): 218-226.

25. FREDRICKSON B L. Positive Emotions Broaden and Build[M]//Elsevier Science \& Technology, 2013.

26. PORATH C, SPREITZER G, GIBSON C, et al. Thriving at work: Toward its measurement, construct validation, and theoretical refinement[J]. Journal of Organizational Behavior, 2012,33(2): 250-275.

27. Baron RM, DA K. The moderator-mediator variable distinction in social psychological research: conceptual, strategic, and statistical considerations[J]. J Pers Soc Psychol, 1986,51(6): 1173-1182. 